\title{
Flow Induced Vibration of Separated Two-Phase Flow Due to Restricting Orifice
}

\author{
Olufemi E. Bamidele, Wael H. Ahmed, Marwan Hassan \\ School of Engineering, University of Guelph \\ Guelph, N1G 2W1, ON, Canada \\ obamidel@uoguelph.ca; ahmedw@uoguelph.ca; mahassan@uoguelph.ca
}

\begin{abstract}
The current work investigates flow-induced vibrations of piping structures with flow restricting orifices due to separated two-phase flow. Air-water flow through a flow restricting orifice with area ratio of 0.25 was experimentally investigated at various superficial velocities ranging from $J_{L}$ from $0.46 \mathrm{~m} / \mathrm{s}$ to $1.3 \mathrm{~m} / \mathrm{s}$ and $J_{\mathrm{G}}$ from $0.76 \mathrm{~m} / \mathrm{s}$ to $1.7 \mathrm{~m} / \mathrm{s}$. The vibration response of the piping structure was captured for stratified-wavy and dispersed annular flow patterns. Also, the time signals of piping displacement and void fraction with the flow structure were analysed. The results show that Flow induced vibrations of piping structures with a flow restricting orifice due to separated two-phase flow due to flow restricting orifice is a strong function of the void fraction upstream of the orifice for stratified-wavy flow pattern. Moreover, the amplitude of vibration at frequency conditions in the neighbourhood of the dominant void fraction frequency reduced with the increase in the gas superficial velocity.
\end{abstract}

Keywords: FIV, Separated flow, Orifice, Stratified-wavy flow, Dispersed annular flow.

\section{Introduction}

Flow induced vibration is an important issue that affects the reliability of structures in industries. Significant cases of wears and failures in these structures have been reported under single and two-phase flow conditions [1], [2]. Unlike single phase flow, two-phase flow is of concern because of the flow unsteadiness. The two-phase flows properties including the void fraction, momentum and density vary across pipe section. This variation in properties depends on the phase distribution also known as the flow pattern. Various types of the two-phase flow patterns exist. This flow patterns may change when two-phase flows through flow controlling devices such as elbow, tee's, valves and orifices [3-5]. In these devices, flow separation and redistribution downstream; increase the pressure fluctuations on the walls of the piping structure. These pressures fluctuations may be large enough to cause significant amplitude levels of the structure. The vibrations may result in fretting wear and failure of the structure. Therefore, it is important to understanding the dynamic behaviour of flow through piping components is essential to the integrity of the components.

Previously, some effort has been reported to relate two-phase flow properties such as pressure fluctuations and momentum to the dynamic response of the piping components including tee's U-bends and elbow[6-8]. The reported works emphasised on the separated and the slug flow patterns $[9,10]$. In the slug flow pattern, the slug impact and the momentum change have been identified as the dominant excitation forces [8]. Also, in the separated flow pattern, the wave impact has been identified as an excitation force [10]. Recently, Bamidele et al.[11] investigated various two-phase flow patterns including bubbly, intermittent and separated flow for the effect of properties such as quality and slip ratio on the vibration amplitudes of piping structures with a flow restricting orifice. Several studies have also been reported on two-phase flow through orifices but, not much has been done on the dynamic response of piping structures with a flow restricting orifice for two-phase flow [12-14]. Also, no work has been done to relate instantaneous void fraction signal with the response of the structure.

The main objective of the current work is to experimentally investigate two-phase flow induced vibration due to separated flow in a piping structure with a flow restricting orifice with an area ratio 0.25 . The stratified-wavy and dispersed annular flow patterns were investigated and an attempt to relate the time signals of piping displacement and void fraction with the flow structure will be made. 


\section{Experiment}

The experimental set-up comprised of a closed air-water loop (figure 1). An orifice of area ratio of 0.25 was installed in a 1-inch pipe to at $2.4 \mathrm{~m}$ downstream of piping structure. Air-water mixture was passed through the pipe at various superficial velocities ranging from $\mathrm{J}_{\mathrm{L}}$ from $0.46 \mathrm{~m} / \mathrm{s}$ to $1.3 \mathrm{~m} / \mathrm{s}$ and $\mathrm{J}_{\mathrm{G}}$ from $0.76 \mathrm{~m} / \mathrm{s}$ to $1.7 \mathrm{~m} / \mathrm{s}$. The separated two-phase flowed through the orifice and the flow induced vibrations of the structure was investigated just downstream of the orifice.

For the two-phase flow dynamics, a particle tracking system which made use of camera and laser sheet (PIV) [15-19] was employed. The investigation was done at the location of collection of vibration data $0.2 \mathrm{~m}$ downstream of the orifice. Seeded ionized water at room temperature was passed through a two-phase flow mixer in which air was added to form an air-water mixture. The mixture preceded through the 1/2inch orifice the horizontal acrylic pipe for analysis. A thin laser sheet was passed through the center of the orifice to create a plane for illumination of the particles (polyamide particles) for easy tracking by a high speed Speed-sense camera mounted perpendicularly to the plane of the laser sheet. The high speed camera was used to track the absolute movement of the particles and to capture 2D images of the air-water mixture as it passed through the laser sheet, downstream the orifice. DANTEC Studio@ data processing software for phase discrimination was employed for image processing. Furthermore, flow visualization was done with the aid of a high speed to analyze flow redistribution through the orifice. The high speed camera was used without the laser to capture the flow from top and side view, upstream and downstream the orifice. The high-speed images were visually checked for flow redistribution.

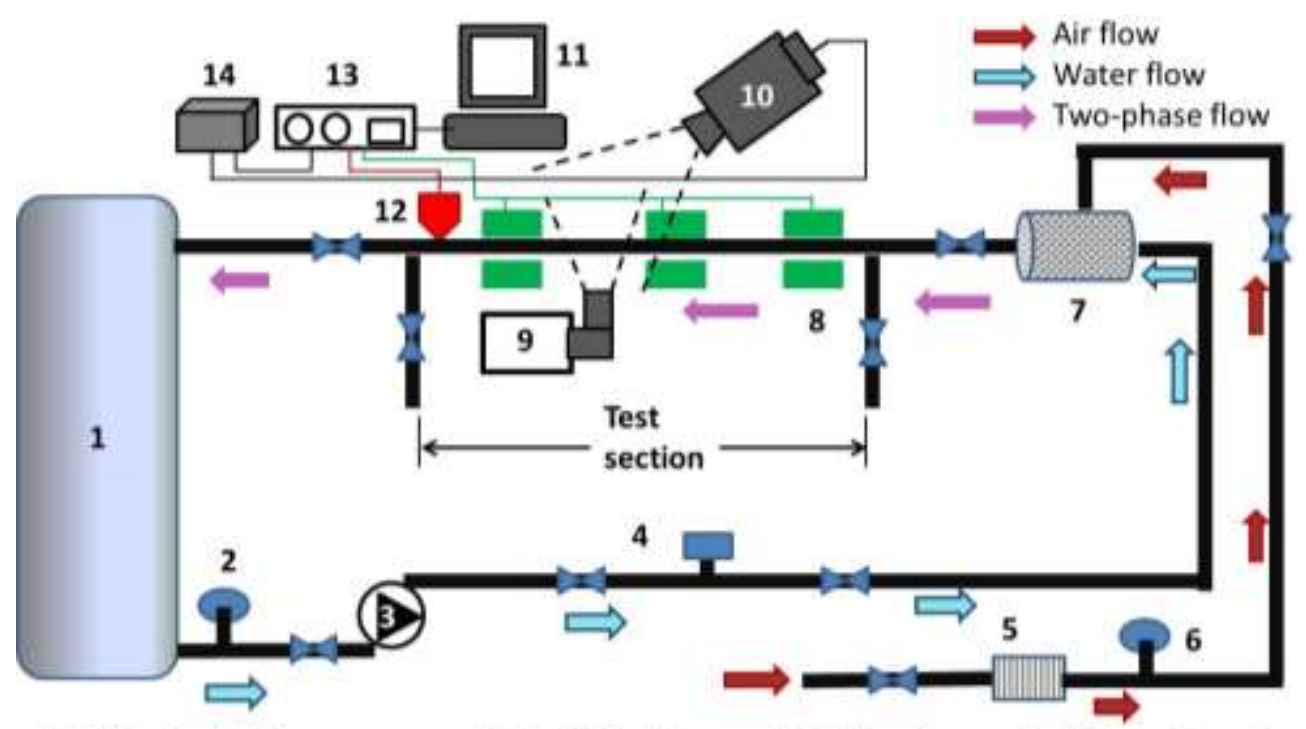

1. Water tank 2. Pressure gauge 3. Centrifugal pump 4. Turbine flow meter 5 . Air rotameter 6. pressure gauge 7. two-phase mixer 8, void fraction sensor 9. PIV LASER 10. High Speed Camera 11. PC 12. Proximity sensor 13, DAQ 14. Synchroniser

Fig. 1: Schematic of two-phase flow Loop. 


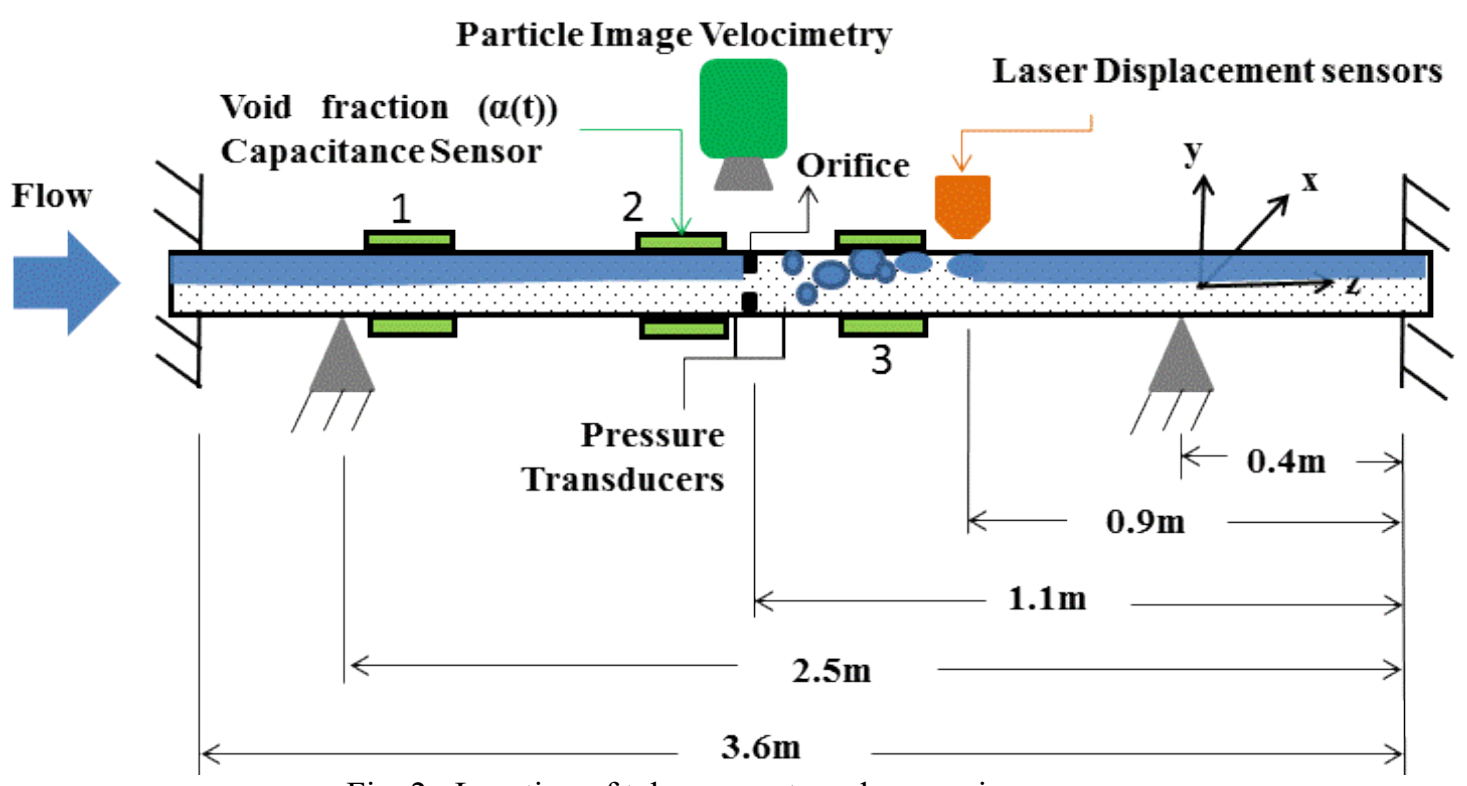

Fig. 2: Location of tube supports and measuring sensors.

In addition to liquid particle tracking using PIV and flow visualization, capacitance and laser displacement sensors were employed to measure the time average void fraction of flow and the flow-induced displacements of piping structure. The vibration data was collected in the vertical direction (y), along a coordinate perpendicular to the direction of flow. The twophase void fractions at various locations along the piping were studied including the fully developed void fraction (location 1 ), the void fraction at the entrance of the orifice (location 2) and the local void fraction at the location of collection of the vibration data (location 3) as shown in figure 2. A concave-type capacitance sensor was employed to measure void fraction for of the flow. Details of this can be found in Ahmed [20]. The void fraction data was collected simultaneously with the vibration data to study the effect of the time varying void fraction data on the vibration data. In addition to this, the high speed camera was synchronized with the void fraction and the vibration signal in order to relate the three signals. The data was processed on MATLAB and their Fast Fourier Transform (FFT) was evaluated and plotted for analysis.

\section{Results and Discussion}

In order to characterize the piping structure for free vibration, a simple pluck test was conducted for the empty pipe structure and another for the pipe filled with stagnant water. A highly damped system was observed with damping ratios of $7.5 \%$ and $8.7 \%$ for the empty and water filled pipe respectively. The dominant natural frequency for the empty pipe structure was $6.6 \mathrm{~Hz}$ for the empty pipe and $6 \mathrm{~Hz}$ for the water filled pipe.

In order to validate the PIV experimental set-up, the velocity profile gotten from PIV analysis of single phase water flow through the orifice was plotted against Smith et al. [21] experimental work and Araoye [22] CFD simulation on ANSYS. The results show good agreement for both cases.

\subsection{General Flow Structure}

After the initial test cases, flow visualization was carried out for flow pattern identification and flow structure analysis. The stratified-wavy and annular dispersed flow patterns were analysed. Representative images for the side and the top view are shown in figure $3 \mathrm{a}$ and $\mathrm{b}$. It is important to note that the top and side view images were taken at different instances of time. In the stratified-wavy flow, as the wave approached the orifice it was observed that the liquid hold-up upstream of the orifice increased and the pipe appeared to be excited at the impact of the wave (figure 1). The force of the wave pushed the liquid jet through the orifice and some backflow was observed because of the lower pressure in the neighbourhood of the orifice downstream. 


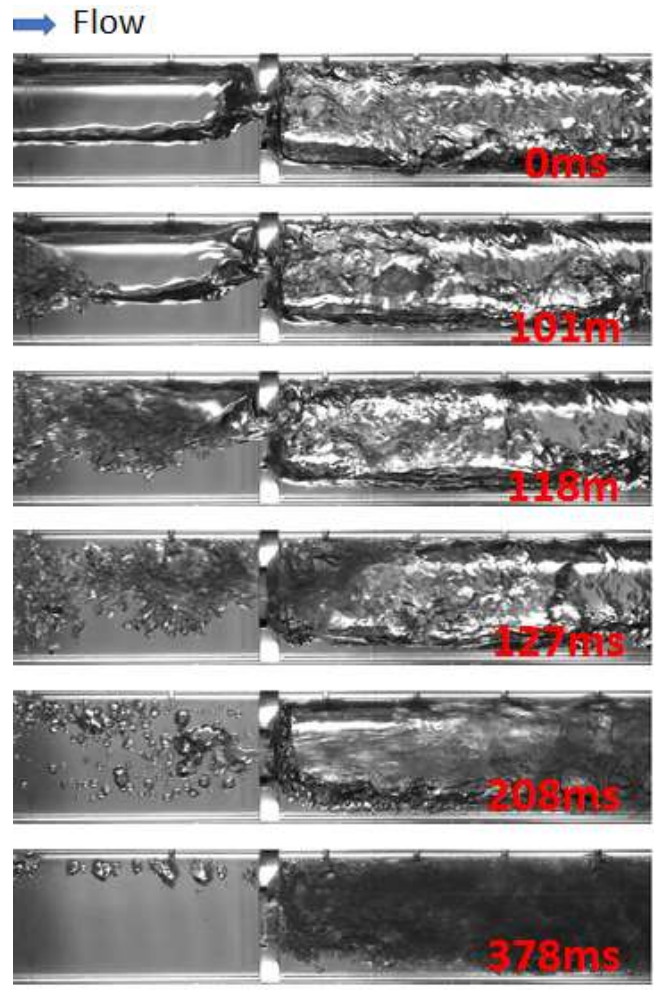

(a) Side View
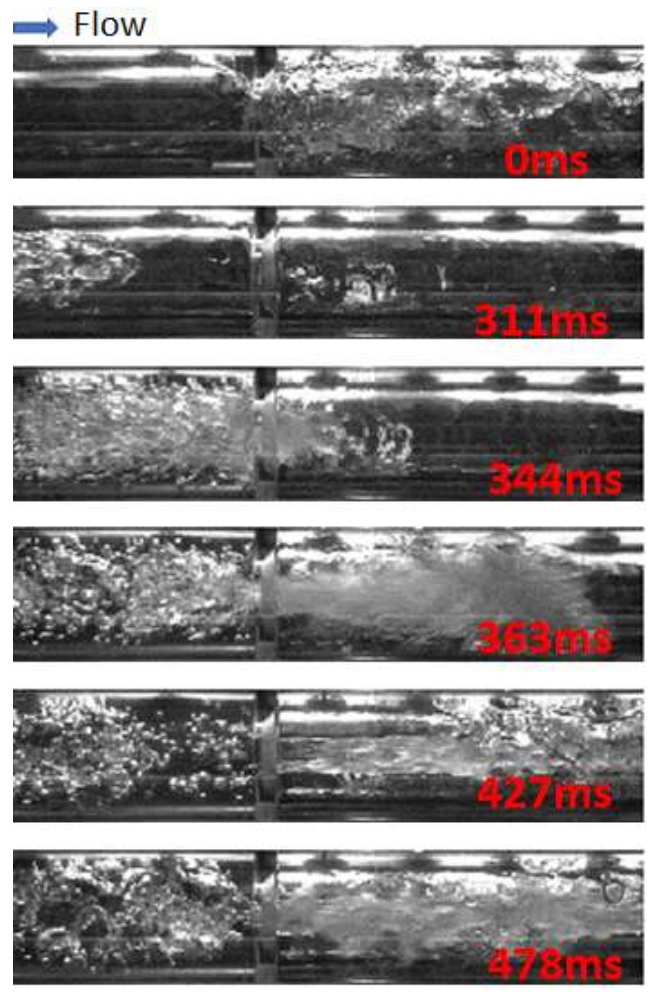

(b) Top View

Fig. 3: Images of stratified-wavy flow through orifice at $J_{L}$ of $0.46 \mathrm{~m} / \mathrm{s}$ and $J_{G}$ of $0.76 \mathrm{~m} / \mathrm{s}$.

The two-phase mixture rolled backwards towards the orifice (figure 3a). Subsequently, the gas phase passed through and stratified-wavy flow was observed downstream of the orifice (figures $3 \mathrm{a}$ and $\mathrm{b}$ ). The top view images (figure $3 \mathrm{~b}$ ) show more symmetric flow compared to the side view in figure 3a. In the case of the annular dispersed flow, similar liquid hold-up and back flow were observed.

The initial flow visualization, PIV analysis was carried out to determine the flow field. Various superficial velocities for liquid and gas were investigated. Sample results are shown in figure 4 . The cases shown in figure 4 show the raw image of the two-phase mixture upstream, the streamline, vectors and vorticity plots. Also, the turbulence intensity is shown the RMS of the velocity coloured by the mean velocity in the direction of flow. The raw image shows broken bubbles downstream of the orifice. The two-phase mixture appeared to be homogeneous. The streamline plots show an axial motion with some backflow at the lower corner of the orifice downstream. This backflow reduced with the increase in the gas superficial velocity from $0.76 \mathrm{~m} / \mathrm{s}$ to $1.7 \mathrm{~m} / \mathrm{s}$. Moreover, the magnitude of the velocity appeared to increase with the increase in the superficial velocity of the gas phase as shown in the vector plots. The turbulence intensity downstream of the orifice increased with the increase in the superficial velocity of the gas. This is expected because the void fraction downstream of the orifice reduced with increase in the gas superficial velocity (figure 5iii). Also, the magnitude of the vorticity at the bottom of the orifice, is reduced at the top part of the orifice with the increase in the superficial velocity of the gas phase. 


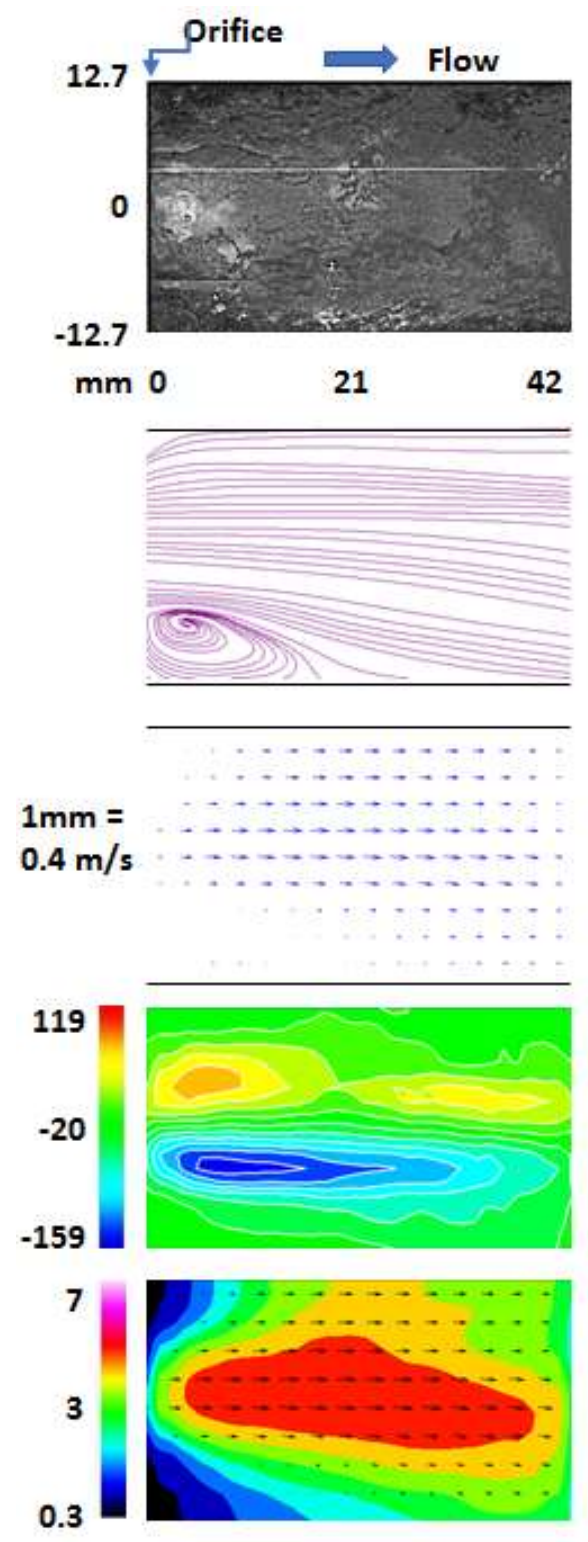

(i)
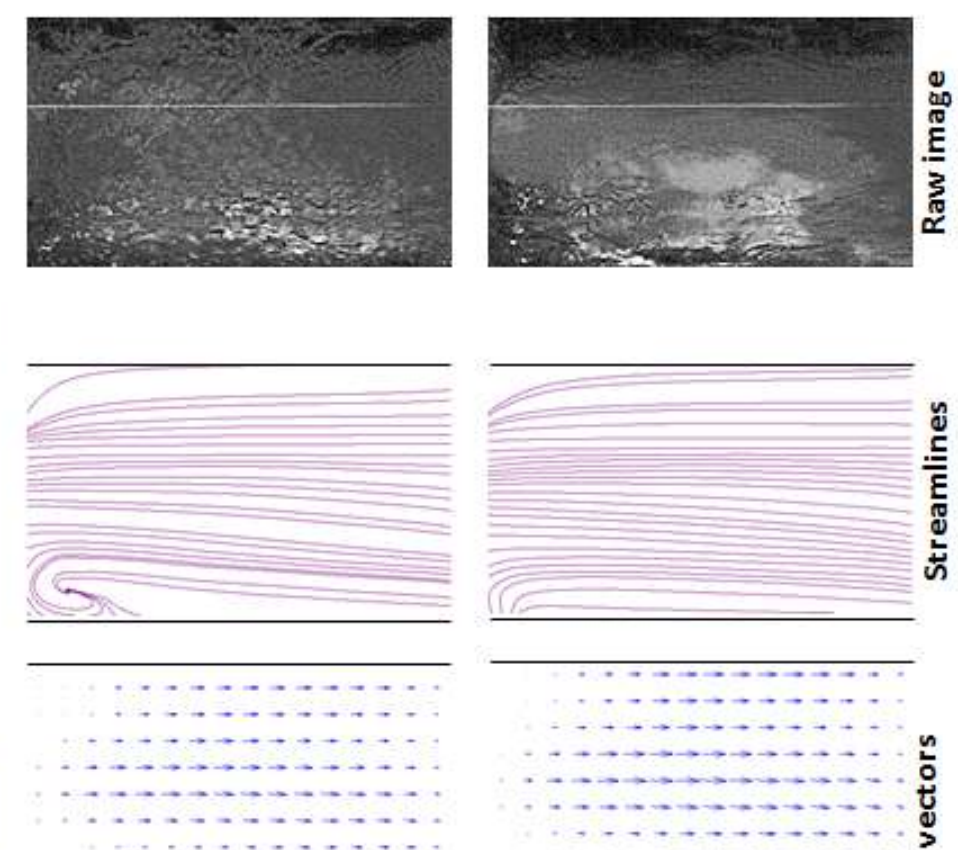

\section{号}
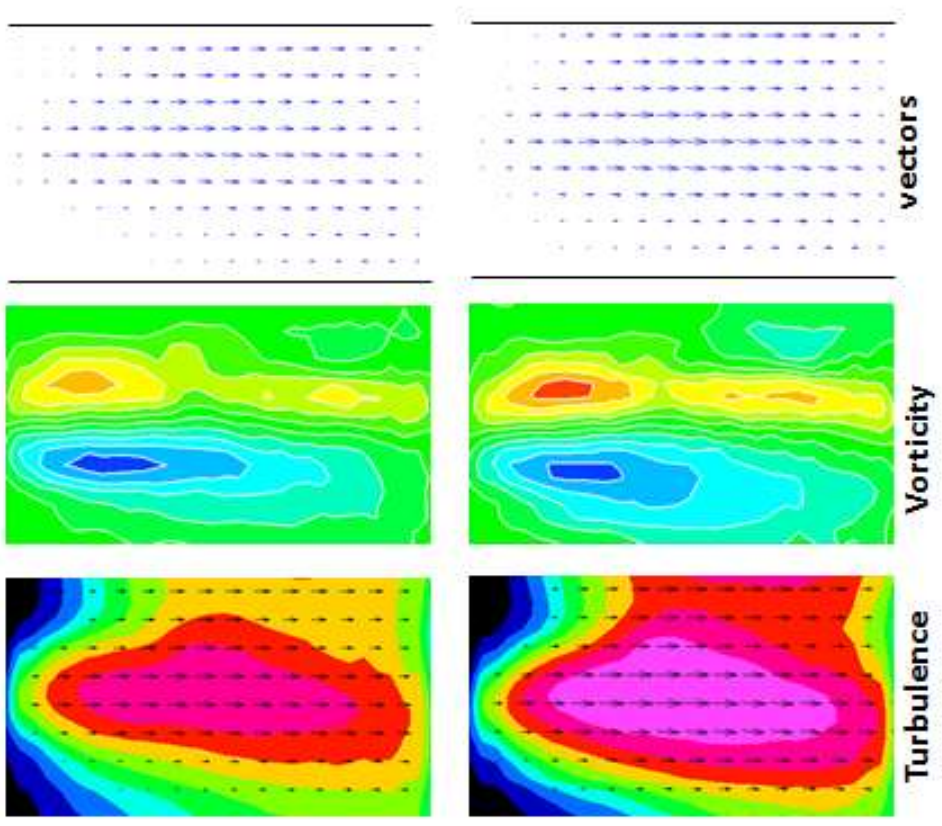

(ii)

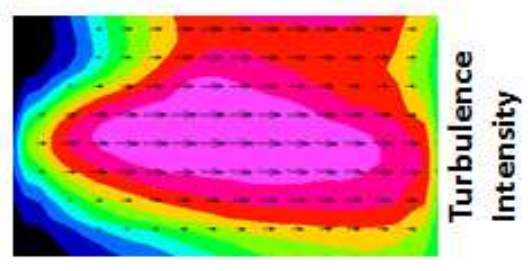

(iii)

Fig. 4: Side view of time average (a) Raw image (b) streamlines (c) Vectors (d) vorticity (e) Turbulence Intensity plots from PIV analysis of stratified-wavy flow downstream of orifice for $\mathrm{J}_{\mathrm{L}}$ at $0.46 \mathrm{~m} / \mathrm{s}$ and $\mathrm{J}_{\mathrm{G}}$ at (i) $0.76 \mathrm{~m} / \mathrm{s}$ (ii) $1.1 \mathrm{~m} / \mathrm{s}$ (iii) $1.7 \mathrm{~m} / \mathrm{s}$.

\subsection{General Vibration}

After the analysis of the flow structure, 15 cases of separated flow were investigated for the effect of the void fraction and superficial velocities on the dynamic response of the structure. Five liquid superficial velocities were investigated from $0.46 \mathrm{~m} / \mathrm{s}$ to $1.3 \mathrm{~m} / \mathrm{s}$. For superficial velocity of the liquid, three superficial velocities of the gas phase were investigated including $J_{\mathrm{G}}$ at $0.76 \mathrm{~m} / \mathrm{s} 1.1 \mathrm{~m} / \mathrm{s}$ and $1.7 \mathrm{~m} / \mathrm{s}$. All the cases studied were in the stratified-wavy and the dispersed annular flow patterns. Representative results are shown in figures 5 and 6. The FFT of the void fraction upstream and at the location of collection of vibration data (figure $5 \mathrm{i}$ and ii) who the frequency of the void fraction while the PDF plots (figure 5 ii and iv) show the probability distribution of the of the gas phase. In all the cases, the observed void fraction frequency was low. Also, excitation frequencies were observed in the neighbourhood of the void fraction frequency and the natural frequency of the piping. For the stratified-wavy flow, an excitation frequency was observed in the neighbourhood of the void fraction 
frequencies upstream and at the location of collection of vibration data (figure 5). The amplitude of vibration of the structure at this frequency was dominant compared to the amplitude of excitation in the neighbourhood of the natural frequency (figure $5 \mathrm{v})$. In the neighbourhood of the natural frequency, the amplitude of excitation increased with the increase in the superficial velocity of the gas phase. On the other hand, in the neighbourhood of the void fraction frequency, the amplitude of excitation decreased with the increase in the superficial velocity of the gas phase. This could be because as more gas was injected into the flow, the flow becomes pure smooth stratified. More so, the excitation in the neighbourhood of this wave also reduced as shown in figure 5. On the other hand, in the dispersed annular flow, the excitation in the neighbourhood of the void frequency and the natural frequency appeared to increase with the increase in the gas flow rate.

Furthermore, the vibration amplitude increased with the increase in the superficial velocity of the gas phase (figure 6). The frequency spectrum of the void fraction increased with the increase in the superficial velocity of the liquid phase. Within the dispersed annular flow pattern, multiple peaks were observed at various frequencies in the FFT of the void fraction. This is mainly because of the unsteadiness in the dispersed annular flow pattern.

\subsection{Time Varying Signals}

The time signals for stratified-wavy flow and dispersed annular flow are shown in figures 7 and 8 . The results show that time response of void fraction upstream and that the shape of the sinusoidal wave in the piping response can be used to predict the two-phase flow pattern that is causing the excitation (figure $7 \mathrm{a}$ and $\mathrm{b}$ ). In the stratified-wavy flow, the timeamplitude signals show that the excitation frequency of the piping structure is around the wave frequency. Furthermore, a lag was observed in the piping response compared to the void fraction. This suggests that higher amplitudes of excitation may be expected toward the end of the wave than the beginning (figure 7a). Multiple vibration frequencies were observed in the dispersed annular flow as shown in figure $7 \mathrm{~b}$ response.
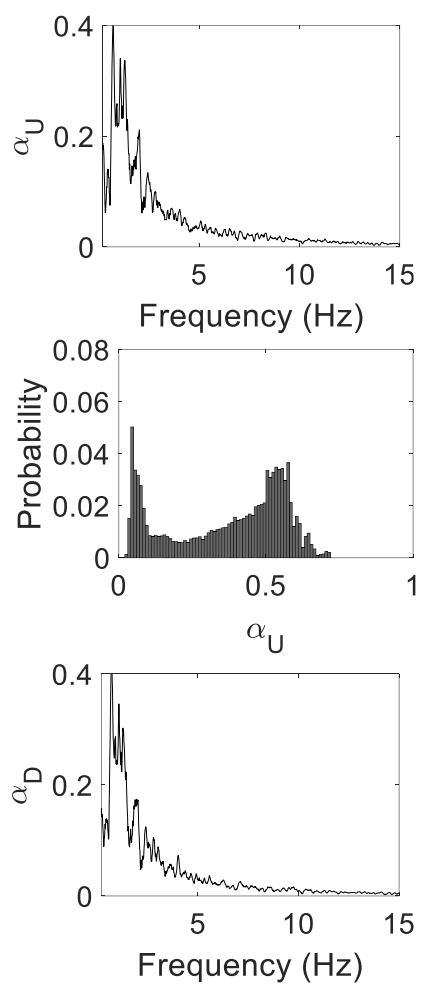
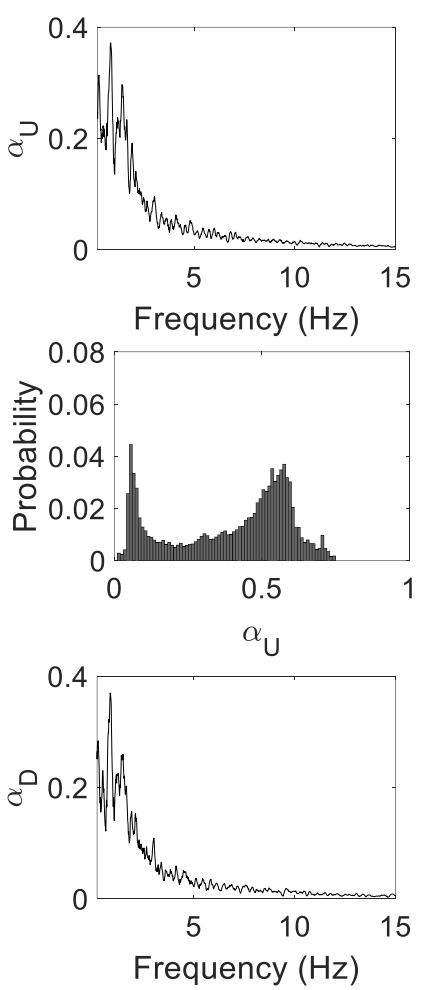

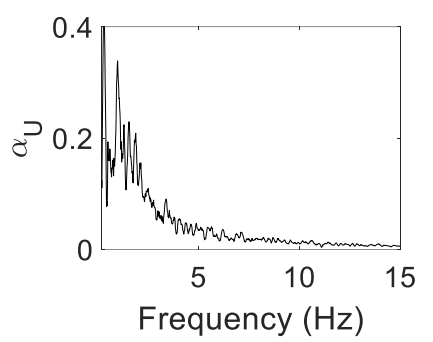

(i)

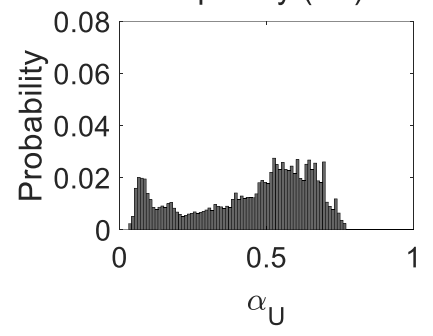

(ii)

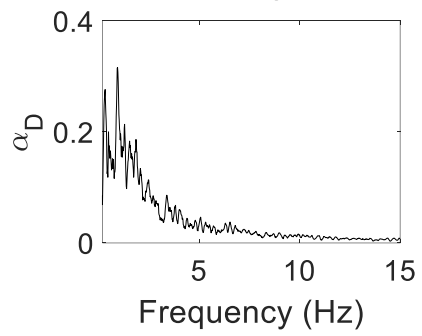



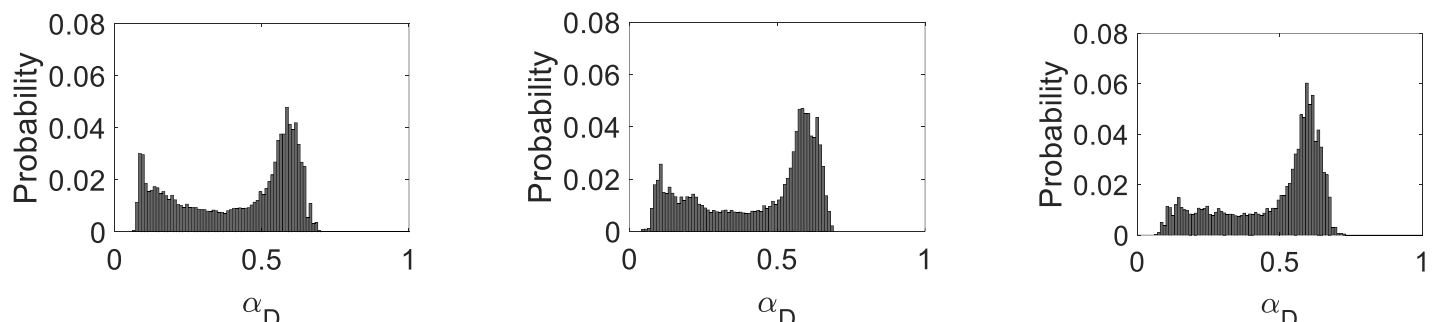

(iv)
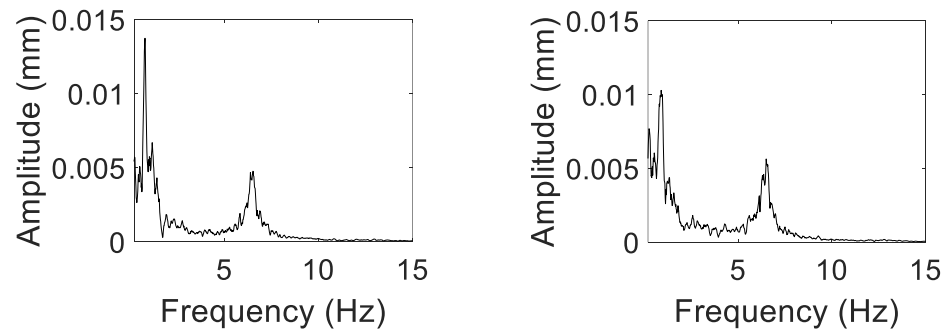

(a)

(b)



(v)

Fig. 5: FFT plots for vibration response and void fraction. PDF of void fraction for $\mathrm{J}_{\mathrm{L}}$ at $0.46 \mathrm{~m} / \mathrm{s}$ and $\mathrm{J}_{\mathrm{G}}$ at (a) $0.76 \mathrm{~ms} /$ (b) $1.1 \mathrm{~m} / \mathrm{s}$ and (c) $1.7 \mathrm{~m} / \mathrm{s}$. (i and ii) FFT and PDF of void fraction upstream, (iii and iv) FFT and PDF of void fraction downstream,(v) FFT of vibrations response.
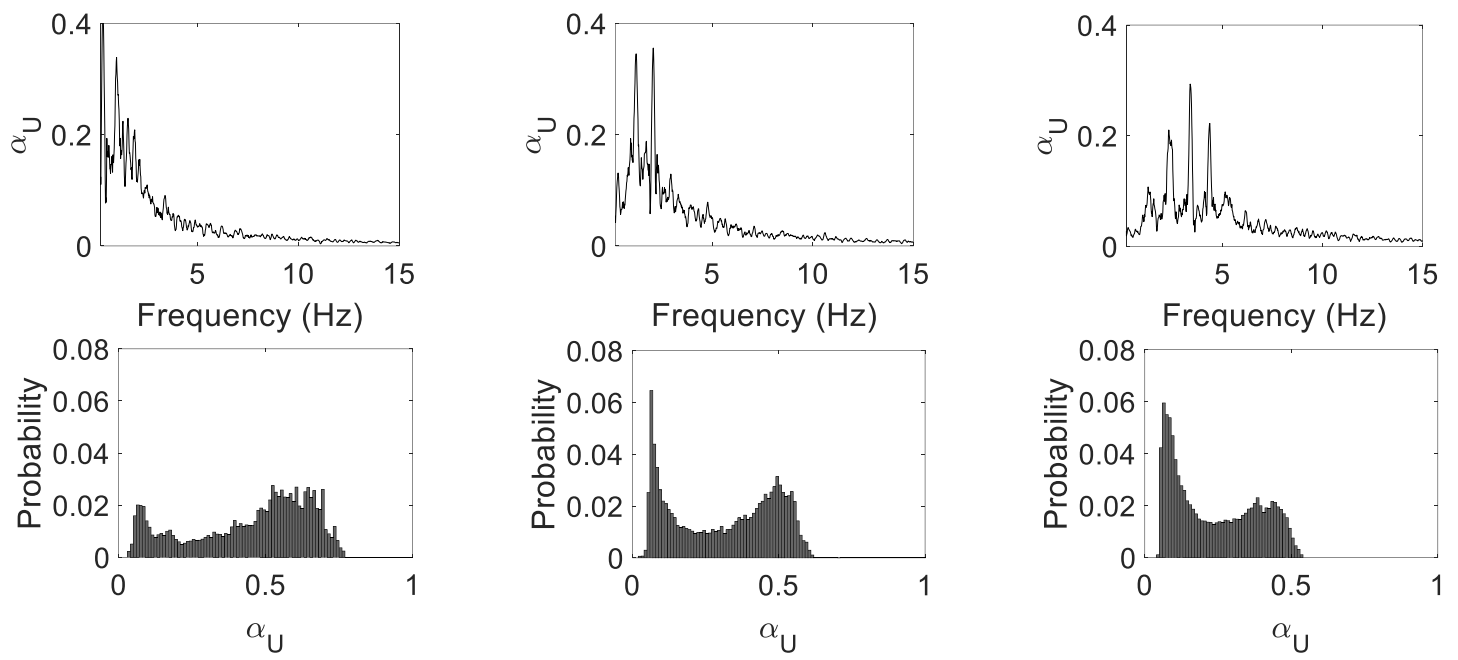

(i)
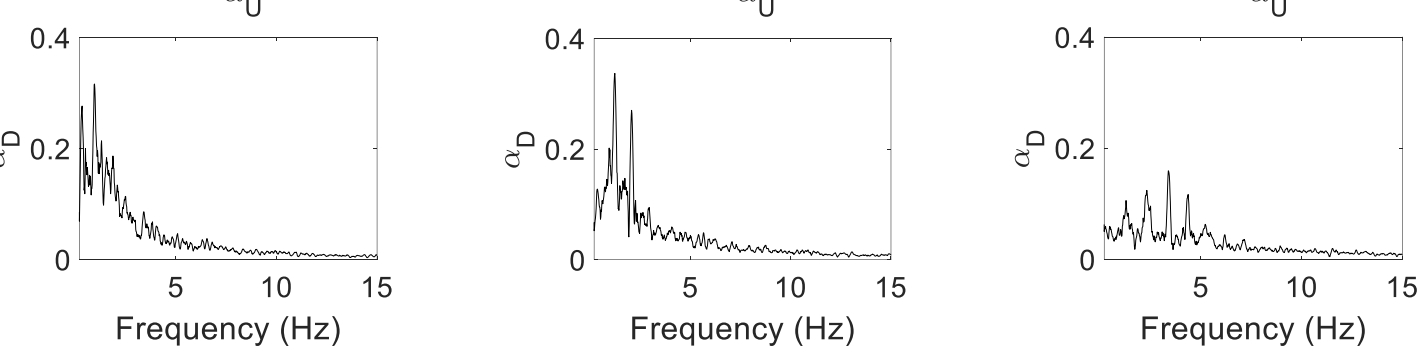

(ii)

(iii) 

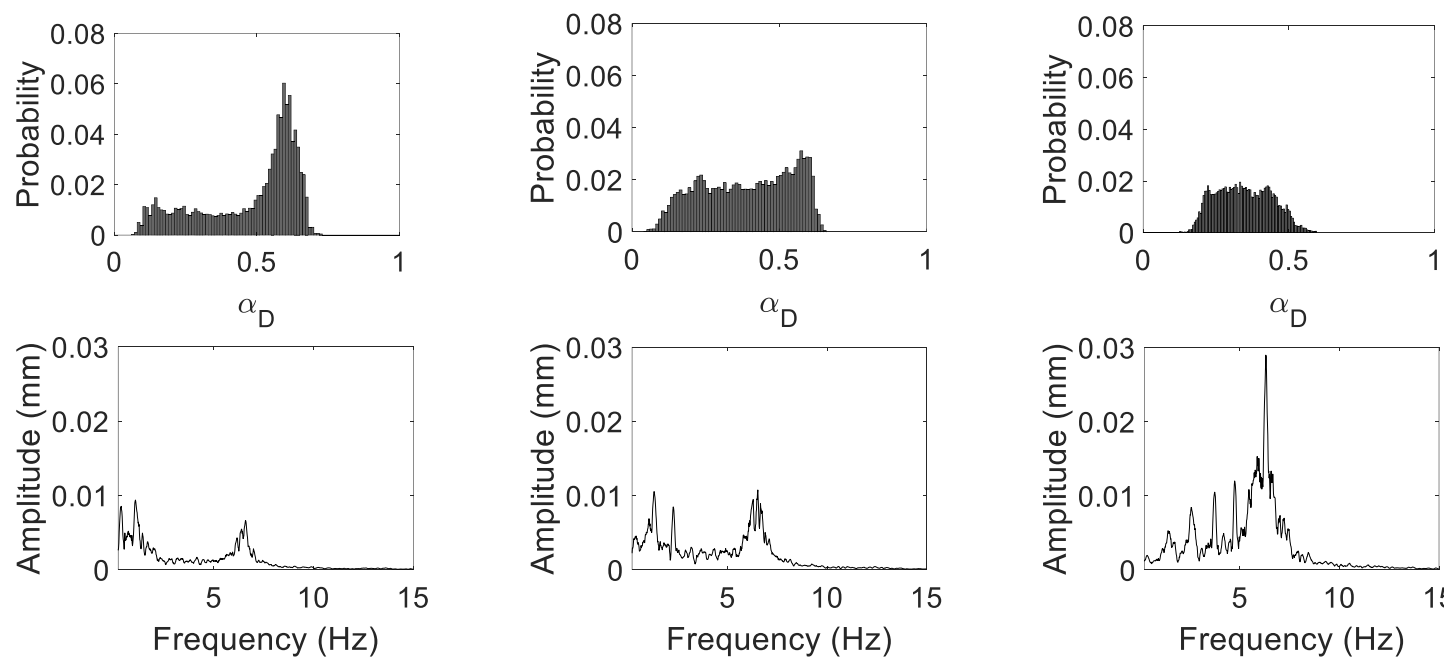

(b)

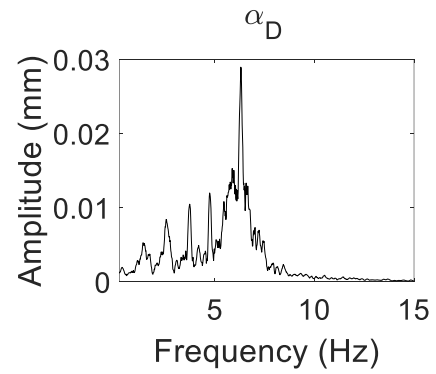

(v)

Fig. 6: FFT plots for vibration response and void fraction. PDF of void fraction for $\mathrm{J}_{\mathrm{G}}$ at $1.7 \mathrm{~m} / \mathrm{s}$ and $\mathrm{J}_{\mathrm{L}}$ at (a) $0.46 \mathrm{~ms} /(\mathrm{b}) 0.82 \mathrm{~m} / \mathrm{s}$ and

(c) $1.3 \mathrm{~m} / \mathrm{s}$. (i and ii) FFT and PDF of void fraction upstream, (iii and iv) FFT and PDF of void fraction downstream,(v) FFT of vibrations response.

After the analysis of the time signals, the high speed camera was synchronized with the vibration sensor and the void fraction sensor to relate the flow structure response with the time signals of the flow characteristics. Sample results for separated flow are shown in figure 8. For clarity, the figure at the top are enlarged of the ones below. It was observed that the excitation of the piping occurred when the gas phase approached the orifice (time $0.14 \mathrm{~s}$ to $0.18 \mathrm{~s}$ ). Also, an increase in the excitation amplitude was found to occur at the end of the wave $(0.26 \mathrm{~s})$.

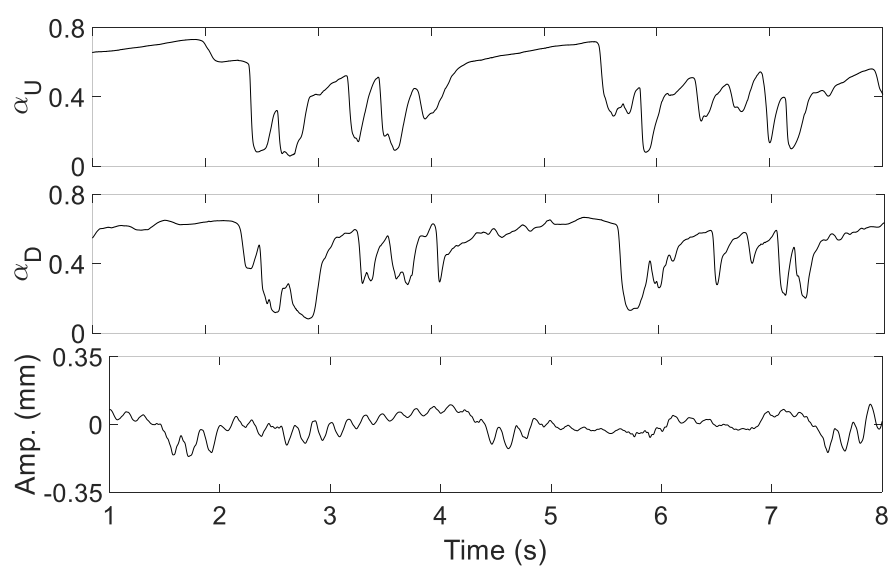

(a)

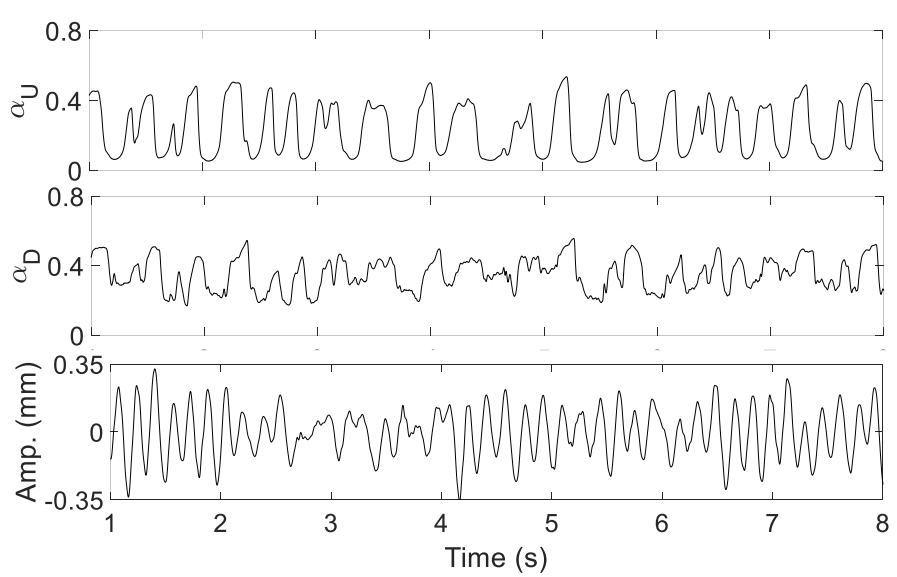

(b)

Fig. 7: Time signal for piping displacement and void fraction for (a) stratified-wavy flow at $\mathrm{J}_{\mathrm{L}}$ of $0.46 \mathrm{~m} / \mathrm{s}$ and $\mathrm{J}_{\mathrm{G}}$ of $1.7 \mathrm{~m} / \mathrm{s}$ (b) Dispersed annular flow at $\mathrm{J}_{\mathrm{L}}$ of $1.3 \mathrm{~m} / \mathrm{s}$ and $\mathrm{J}_{\mathrm{G}}$ of $1.7 \mathrm{~m} / \mathrm{s}$. 

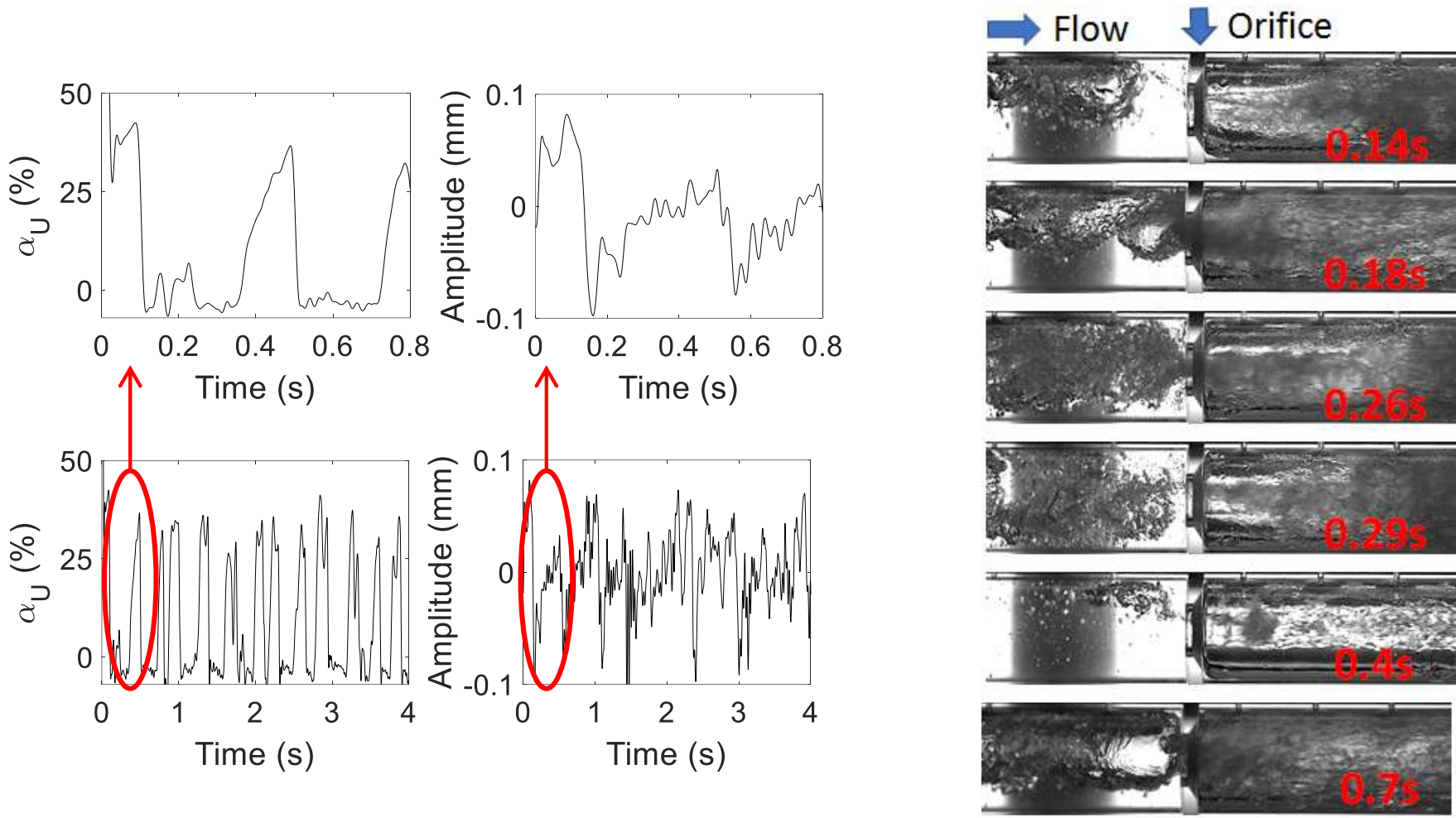

Fig. 8: Time varying signals of amplitude of piping displacement and time stamped images for separated flow at $\mathrm{J}_{\mathrm{L}}=1.1 \mathrm{~m} / \mathrm{s}$ and $\mathrm{J}_{\mathrm{G}}=1.7 \mathrm{~m} / \mathrm{s}$.

\section{Conclusion}

- Flow induced vibrations of pipings structures with a flow restricting orifice due to separated two-phase flow is dependent on the upstream void fraction.

- Two main frequencies of excitation were observed in Stratified-wavy flow. The first was in the neighbourhood of the void fraction frequency and the other in the nighbourhood of the natural frequency of the structure.

- In the dispersed annular flow, multiple excitation frequencies were observed in the neighbourhood of the void fraction frequency.

- The vibration signal was found to depend on the flow pattern changes and the instantaneous void fraction.

- In the stratified-wavy flow pattern, the vibration amplitude reduced with the increase in the gas superficial velocity.

\section{Acknowledgements}

The authors wish to acknowledge the support received from the Natural Sciences and Engineering Research Council of Canada (NSERC) during the course of this study.

\section{References}

[1] A. R. Kabiri-Samani, "Flunctuation of Air-Water Two- Phase Flow in Horizontal and Inclined Water pipes," ASME J. fluid Eng., vol. 129, no. 1, pp. 1-14, 2005.

[2] M. A. Rahman, T. Heidrick, and B. A. Fleck, "A Critical Review of Advanced Experimental Techniques to Measure Two-Phase Gas/Liquid Flow,” Open Fuels Energy Sci. J., vol. 2, no. 1, pp. 54-70, Sep. 2009.

[3] J. D. Talley, T. Worosz, S. Kim, and J. R. J. Buchanan, "Characterisation of Horizontal Air-Water Two-Phase flow in a round Pipe Part 1- Flow Visualization," Int. J. Multiph. flow, vol. 76, pp. 212-222, 2015.

[4] J. D. Talley, T. Worosz, and S. Kim, "Characterization of horizontal air-water two-phase flow in a round pipe part II: Measurement of local two-phase parameters in bubbly flow," Int. J. Multiph. Flow, vol. 76, pp. 223-236, 2013. 
[5] L. C. Ruspini, C. P. Marcel, and A. Clausse, "Two-phase flow instabilities: A review," Int. J. Heat Mass Transf., vol. 71, pp. 521-548, 2014.

[6] M. J. Pettigrew and C. E. Taylor, "Two-phase flow-induced vibration: An overview," J. Press. Vessel Technol. Trans. ASME, vol. 116, no. 3, pp. 233-253, 1994.

[7] M. Siba, W. Wanmahmood, M. Zaki Nuawi, R. Rasani, and M. Nassir, "Flow-induced vibration in pipes: Challengess and solutions - A review," J. Eng. Sci. Technol., vol. 11, no. 3, pp. 362-382, 2016.

[8] S. Miwa, M. Mori, and T. Hibiki, "Two-phase flow induced vibration in piping systems," Prog. Nucl. Energy, vol. 78, no. 2015, pp. 270-284, 2015.

[9] L. Wang, Y. Yang, Y. Li, and Y. Wang, "Dynamic behaviours of horizontal gas-liquid pipes subjected to hydrodynamic slug flow : Modelling and experiments," Int. J. Press. Vessel. Pip., vol. 161, no. December 2017, pp. 50-57, 2018.

[10] Y. Liu, S. Miwa, T. Hibiki, M. Ishii, and H. Morita, "Experimental study of internal two-phase flow induced fluctuating force on a 90 degree elbow," Chem. Eng. Sci., vol. 76, pp. 173-187, 2012.

[11] O. E. Bamidele, W. H. Ahmed, and M. Hassan, "Two-phase flow induced vibration of piping structure with flow restricting orifices," Int. J. Multiph. Flow, vol. 113, pp. 59-70, 2019.

[12] G. Kojasoy, F. Landis, P. Kwame-Mensah, and C. T. Chang, "Two-phase pressure drop in multiple thick- and thinorifice plates," Exp. Therm. Fluid Sci., vol. 15, no. 4, pp. 347-358, 1997.

[13] C. Alimonti, G. Falcone, and O. Bello, "Two-phase flow characteristics in multiple orifice valves," Exp. Therm. Fluid Sci., vol. 34, no. 8, pp. 1324-1333, 2010.

[14] H. J. Zhang, S. J. Lu, and G. Z. Yu, "An investigation of two-phase flow measurement with orifices for low-quality mixtures," Int. J. Multiph. Flow, vol. 18, no. 1, pp. 149-155, 1992.

[15] S. Eckert, A. Cramer, and G. Gerbeth, "Velocity Measurement Techniques for Liquid Metal Flows," Magnetohydrodyn. Evol. Trends, pp. 275-294, 2007.

[16] P. Buchhave, "Particle Image Velocimetry," Exp. Therm. Fluid Sci., vol. 5, pp. 586-604, 1992.

[17] J. Novotn, J. Nožička, J. Adamec, and L. Novákov, "Measurement of Two Phase Flow," Acta Polytech., vol. 45, no. 3, pp. 73-76, 2005.

[18] A. L. Tassin, C.-Y. Li, S. L. Ceccio, and L. P. Bernal, "Velocity field measurements of cavitating flows," Exp. Fluids, vol. 20, no. 2, pp. 1-6, 1995.

[19] T. Ning, F. Guo, B. Chen, and X. Zhang, "PIV measurement of turbulent bubbly mixing layer flow with polymer additives," J. Phys. Conf. Ser., vol. 147, pp. 012014, 2009.

[20] W. H. Ahmed, "Capacitance sensors for void-fraction measurements and flow-pattern identification in air-oil twophase flow," IEEE Sens. J., vol. 6, no. 5, pp. 1153-1163, 2006.

[21] S. Eiamsa-ard, A. Ridluan, P. Somravysin, P. Promvonge, and N. Chok, "Numerical investigation of turbulent flow through a circular orifice," KMITL Sci. J., vol. 8, no. 1, pp. 44-50, 2008.

[22] A. A. Araoye, "Investigation of Flow and Erosion Characteristics through a Set of Restricting Orifices," M. S. Thesis, King Fahd University of Petroleum and Minerals, Dhahran, Saudi Arabia, 2015. 